\title{
Analisis Penerapan Program GMP dan 5P Terhadap Kinerja Karyawan di PT Kalbe Morinaga Indonesia
}

\author{
Halily Sofyan Al Hasan \\ Sekolah Tinggi Teknologi Wastukancana \\ Email: halilysofyan@stt-wastukancana.ac.id \\ Muhammad Ali Akbar \\ Sekolah Tinggi Teknologi Wastukancana \\ Email:maliakbar@stt-wastukancana.ac.id \\ Ade Elza Surachman \\ Sekolah Tinggi Ilmu Ekonomi Wibawa Karta Raharja \\ Email: adeelza@stiewikara.ac.id
}

\begin{abstract}
This study aim is to know the effect of the implementation of Good Manufacturing Practices Program, 5P Program related on Employee Performance at PT. Kalbe Morinaga Indonesia. This research is located in PT. Kalbe Morinaga Indonesia with 390 people population and the sample taken is 84 people using stratified random sampling technique with Slovin formula which is conducted from May to June 2018. Approachment to data analyze using Partial Least Square (PLS), namely Smart-PLS 3.0. Based on the analysis results obtained that Good Manufacturing Practices Program has a positive effect on Employee Performance and 5P Program also has a positive effect on Employee Performance.
\end{abstract}

Keywords: Good manufacturing practices program, 5P program.

\section{Abstrak}

Tujuan penelitian ini adalah mengetahui pengaruh penerapan Program Good Manufacturing Practices dan Program 5P terhadap Kinerja Karyawan di PT. Kalbe Morinaga Indonesia. Penelitian ini berlokasi di PT. Kalbe Morinaga Indonesia dengan jumlah populasi 390 orang dan sampel yang diambil adalah 84 orang menggunakan teknik pengambilan sampel stratified random sampling dengan menggunakan rumus slovin yang dilakukan dari bulan Mei sampai Juni 2018. Pendekatan untuk menganalisis data menggunakan Partial Least Square (PLS) yaitu Smart-PLS 3.0. Berdasarkan hasil analisis diperoleh bahwa Program Good Manufacturing Practices berpengaruh positif terhadap Kinerja Karyawan dan Program 5P juga berpengaruh positif terhadap Kinerja Karyawan.

Kata kunci: Program good manufacturing practices, Program 5P.

\section{Pendahuluan}

PT. Kalbe Morinaga Indonesia merupakan perusahaan susu formula bayi dan formula lanjutan yang perlu diproduksi sesuai dengan pedoman cara produksi yang baik untuk menghasilkan produk yang aman dan bermutu. Keamanan pangan merupakan salah satu aspek mutu yang sangat penting dan tidak bisa ditawar. Perusahaan ini diharuskan untuk menangani produk dalam kondisi higienis sehingga makanan tersebut aman, sehat dan berkualitas untuk dikonsumsi oleh konsumen yang memenuhi persyaratan sebagai produk bersih dan higienis, produk tidak mengandung kontaminan, produk tidak membuat sakit setelah dimakan, serta produk yang memenuhi persyaratan konsumen dan pemerintah.

Untuk mencapai tujuan tersebut maka PT. Kalbe Morinaga Indonesia menggabungkan antara program Good Manufacturing Practices dengan program 5P menjadi satu rancangan Program GM5P. Good Manufacturing Practices (GMP) adalah sistem dasar yang digunakan sebagai pedoman cara kerja produksi yang higienis mulai dari 
penanaman, pemanenan, pengolahan hingga pendistribusian sehingga produk aman dikonsumsi dan 5P merupakan program Pemilahan, Penataan, Pembersihan, Penstandardisasian dan Pembiasaan. Hal tersebut dikarenakan penerapan cara produksi yang higienis akan berjalan dengan lebih baik dengan menanamkan kebiasaan bekerja yang tertib, tertata sistematis hingga bagian kerja yang terkecil melalui penerapan prinsip $5 P$.

Penerapan program Good Manufacturing Practicesdan 5P yang baik harus didasari oleh komitmen dari seluruh pihak yang terkait. Selain itu, untuk menjamin pelaksanaan program Good Manufacturing Practices dan 5P dilakukan dengan baik juga perlu dilakukan dengan proses monitoring/audit. Dari hasil monitoring/audit dengan standar penilaian yang ditetapkan oleh perusahaan sebetulnya semua departemen sudah memenuhi kriteria diatas standard. Namun demikian, pada pelaksanaannya masih ada beberapa karyawan yang dalam proses kerjanya belum sepenuhnya menerapkan nilainilai Good Manufacturing Practices dan 5P dan juga kondisi lingkungan kerja yang tidak sesuai dengan nilai-nilai Good Manufacturing Practices dan 5P, hal ini bisa diindikasikan dari beberapa temuan pelanggaran/penyimpangan yang ada pada saat audit maupun monitoring.

Kegiatan 5S diterapkan agar karyawan mampu memberikan hasil produktivitas yang lebih tinggi dan mutu yang lebih baik karena orang yang mempedulikan pekerjaannya mampu melaksanakan tugasnya dengan lebih baik (Osada, 2011). Kemudian penerapan budaya kerja 5R berpengaruh signifikan dan positif terhadap semangat kerja dan kinerja karyawan (Sari, 2015). Sedangkan untuk program Good Manufacturing Practices memang belum ada penelitian yang menyebutkan kaitannya terhadap kinerja karyawan sehingga hal tersebut merupakan variabel yang menarik untuk diteliti. Dari latar belakang di atas, maka penelitian ini memiliki perumusan sebagai berikut: (1) bagaimana pengaruh penerapan Program Good Manufacturing Practices terhadap kinerja karyawan di PT. Kalbe Morinaga Indonesia; dan (2) bagaimana pengaruh penerapan Program 5P terhadap kinerja karyawan di PT. Kalbe Morinaga Indonesia.

\section{Literature Review}

Good Manufacturing Practices (GMP) merupakan pedoman cara memproduksi makanan yang baik pada seluruh rantai makanan, mulai dari produksi primer sampai konsumen akhir dan menekankan hygiene pada setiap tahap pengolahan. Good Manufacturing Practices (GMP) berisi penjelasan-penjelasan tentang persyaratan minimum dan pengolahan umum yang harus dipenuhi dalam penanganan bahan pangan di seluruh mata rantai pengolahan dari mulai bahan baku sampai produk akhir (Sutikno, 2017).

Penerapan GMP dapat mengacu berbagai referensi, namun sejauh ini tidak ada standar internasional yang bersifat oficial seperti halnya standar ISO. Oleh karena itu, berbagai negara dapat mengembangkan standar GMP tersendiri, seperti di Indonesia terdapat berbagai standar GMP yang di terbitkan oleh BPOM (Badan Pengawasan Obat dan Makanan) sesuai dengan jenis produk yang dihasilkan. Sebagai contoh beberapa standar GMP tersebut:

1) Standar GMP untuk industri obat-obatan disebut dengan CPOB (Cara Pembuatan Obat yang Baik) 
2) Standar GMP untuk industri makanan disebut dengan CPMB (Cara Pembuatan Makanan yang Baik)

3) Standar GMP untuk industri kosmetik disebut dengan CPKB (Cara Pembuatan Kosmetik yang Baik)

4) Standar GMP untuk industri obat tradisional disebut dengan CPOTB (Cara Pembuatan Obat Tradisional yang Baik)

Tujuan dilaksanakannya praktik Good Manufacturing Practices (GMP) adalah untuk memberikan paduan tata cara khusus (spesific codes) yang diperlukan bagi setiap rantai pangan, proses pengolahan, atau penanganan komoditi bahan pangan untuk mencegah terjadinya kesalahan dan meningkatkan prinsip pelaksanaan persyaratan hygiene yang spesifik bagi masing-masing bidang tersebut di atas (Winarno, 2008). Penerapan praktik atas Good Manufacturing Practices memiliki keuntungan sebagai berikut: (a) menjamin kualitas dan keamanan pangan; (b) meningkatkan kepercayaan dalam keamanan produk dan produksi; (c) mengurangi kerugian dan pemborosan; (d) menjamin efisiensi penerapan HACCP; dan (e) memenuhi persyaratan peraturan/spesifikasi/standar.

Untuk maksud tersebut perlu dilakukan identifikasi terhadap titik-titik penting dari rantai penanganan system hygiene pangan yang dapat diaplikasikan di berbagai tahapan dalam rantai pangan yaitu sejak budidaya sampai pangan dikonsumsi, demi untuk mencapai tujuan dalam memastikan bahwa pangan yang dimaksud aman dan pantas untuk dikonsumsi manusia.

Good Manufacturing Practices (GMP) merupakan suatu pedoman cara memproduksi makanan pabrik, bangunan, produk akhir, peralatan pengolahan, bahan produksi, hygiene personal, pengendalian proses pengolahan, fasilitas sanitasi, label, keterangan produk, penyimpanan, pemeliharaan sarana pengolahan dan kegiatan sanitasi, laboratorium, kemasan dan transportasi (Thaheer, 2008).

Program 5P merupakan 5 (lima) langkah sederhana untuk memperbaiki kondisi kerja yang diberi nama berdasarkan dari huruf awal kelima langkah tersebut, dalam bahasa jepang disebut sebagai (SEIRI + SEITON + SEISO + SEIKETSU + SHITSUKE) yang diterjemahkan ke dalam bahasa Indonesia yang berarti Pemilahan, Penataan, Pembersihan, Penstadardisasian dan Pembiasaan. 5S merupakan gerakan yang berasal dari kebulatan tekad untuk mengadakan pemilahan di tempat kerja, mengadakan penataan, pembersihan, memelihara kondisi yang mantap dan memelihara kebiasaan yang diperlukan untuk melaksanakan pekerjaan dengan baik (Osada, 2011).

\section{1) Pemilahan (Seiri)}

Seiri adalah pemilahan alat dan barang berdasarkan jumlah, kondisi, dan perannya dalam operasi produksi. Salah satu langkah untuk menerapkan seiri dalam lingkungan kerja adalah dengan sistem Red Tag/Label Merah (Hirano, 1996). Sistem Red Tag berfungsi untuk memberikan penanda berupa label merah pada alat dan barang yang tidak digunakan dan/rusak (Tonic, Arsovski, Djapan, \& Macuzic, 2014). Alat dan barang yang sudah diberi label merah selanjutnya akan dipindahkan pada lokasi penampungan khusus untuk ditindaklanjuti. Definisi dari pemilahan adalah: (a) memisahkan barang yang perlu dengan barang yang tidak perlu; (b) menyingkirkan barang yang tidak perlu. Tujuan dari 
Pemilahan adalah menghindari adanya barang-barang berserakan, bertumpuk, terlalu lama disimpan atau tercecer.

\section{2) Penataan (Seiton)}

Seiton adalah eliminasi pemborosan waktu dengan menata alat dan barang dengan teratur sehingga alat dan barang mudah ditemukan dan pengembalian alat dan barang pada tempatnya juga mudah dilakukan. Pembuatan garis benda pada lantai dapat membantu pengaturan letak alat dan barang sehingga penempatan alat dan barang menjadi lebih teratur. Alat dan barang juga sebaiknya diberikan label nama untuk mempermudah identifikasi oleh pekerja. Peta benda dibuat sebagai standar dalam penempatan alat dan barang dalam suatu area produksi (Hirano, 1996). Tujuan dan Manfaat Penataan adalah: (a) menghilangkan ketidakpastian atas peletakan barang; dan (b) mengurangi risiko kehilangan atau kesalahan pengambilan.

\section{3) Pembersihan (Seiso)}

Seiso adalah pembersihan tempat kerja dan juga peralatan kerja agar kotoran dan debu tidak menumpuk. Salah satu langkah dalam menerapkan seiso adalah dengan menyiapkan alat kebersihan pada lokasi yang mudah dijangkau oleh pekerja agar pekerja dapat menggunakan alat kebersihan tersebut dan dapat mengembalikannya dengan mudah (Hirano, 1996). Tujuan dan manfaat pembersihan adalah: (a) mencegah kontaminasi; (b) menjaga kesehatan dan keselamatan kerja; (c) menciptakan tempat kerja yang indah dan nyaman; (d) mencegah kerusakan terhadap benda kerja; dan (e) meningkatkan semangat para pekerja.

\section{4) Penstandardisasian (Seiketsu)}

Seiketsu adalah pembuatan standarisasi terhadap keadaan yang sudah terpilah, tertata dan bersih dengan mengikuti disiplin 3P yang telah dilaksanakan. Seiketsu adalah manajemen visual untuk merawat nilai seiri, seiton, dan seiso. Manajemen visual berfungsi untuk mempermudah pekerja mengetahui kondisi pekerjaan yang ideal, baik dari segi kerapihan lokasi kerja (seiri dan seiton) maupun segi kebersihan (seiso). Dasar penerapan seiketsu adalah menjadikan seiri, seiton, dan seiso (3S) sebagai kebiasaan dalam kehidupan sehari-hari. Penerapan seiketsu juga menggunakan pendekatan preventif untuk mencegah terjadinya pelanggaran nilai 3S secara terus-menerus (Hirano, 1996). Tujuan dan manfaat penstandardisasian adalah: (a) memastikan kondisi 3P tetap terjaga; (b) menjaga lingkungan dalam kondisi yang tetap selalu baik; dan (c) menjaga kualitas hasil kerja. Hal-hal yang perlu dilibatkan dalam aturan penstandarisasian adalah: (i) Standar Keselamatan; (ii) Standar Pembersihan; (iii) Standar Pelabelan; (iv) Standar Warna; dan (v) Standar Garis.

\section{5) Pembiasaan (Shitsuke)}

Shitsuke merupakan tahapan dimana langkah 1-4 (4P) dilakukan ke secara berkesinambungan dan rutin sehingga pelaksanaan 5P dapat terus terjaga. Shitsuke menyatakan bahwa shitsuke adalah pembiasaan nilai 5S dalam kehidupan sehari-hari, baik dalam pekerjaan maupun kehidupan di luar pekerjaan seperti di rumah. Pembiasaan ini bertujuan menjadikan 5S sebagai dasar dalam kehidupan sehari-hari dan menanamkan sikap pada pekerja untuk tidak menjadikan penerapan $5 \mathrm{~S}$ sebagai beban dalam pekerjaan. Penerapan shitsuke ditentukan oleh komitmen bersama suatu perusahaan, baik dari pekerja maupun dari pihak manajemen perusahaan untuk menjadikan $5 \mathrm{~S}$ sebagai bagian dari perusahaan (Hirano, 1996). Pihak manajemen perusahaan dapat menciptakan kondisi 
atau struktur untuk mendukung penerapan 5S di perusahaaan. Salah satu hal yang dapat dilakukan oleh pihak manajemen adalah dengan menciptakan kompetisi 5S. Kompetisi 5S mengajak seluruh pihak untuk berlomba dalam menerapkan $5 \mathrm{~S}$ dalam pekerjaan sehari-hari. Hal ini akan memicu pihak karyawan untuk mengadakan persaingan sehat satu sama lain dalam penerapan $5 \mathrm{~S}$, dan secara tidak langsung membiasakan penerapan Shitsuke dan 5S pada kehidupan sehari-hari.

Kinerja berasal dari kata prestasi kerja (job performance) yaitu hasil kerja secara kualitas dan kuantitas yang dicapai oleh seorang pegawai dalam melaksanakan tugasnya sesuai dengan tanggung jawab yang diberikan kepadanya (Mangkunegara, 2013). Sedangkan, indikator kinerja disebut sebagai ukuran kuantitatif yang menggambarkan tingkat pencapaian suatu sasaran atau tujuan yang telah ditetapkan, dengan memperhitungkan indikator masukan (inputs), keluaran (outputs), hasil (outcomes), manfaat (benefits) dan dampak (impacts).

Hasil kerja yang dapat dicapai seseorang atau sekelompok orang dalam organisasi, sesuai dengan wewenang dan tanggung jawab masing-masing dalam upaya mencapai tujuan organisasi bersangkutan secara legal, tidak melanggar hukum dan sesuai dengan moral dan etika (Sedarmayanti, 2014).

Beberapa penelitian terdahulu yang telah dilakukan antara lain: (1) Penerapan Budaya 5S dan Pengaruhnya terhadap Kinerja Karyawan dengan metode penelitian (SPSS) Regresi Linier Berganda. Hasil penelitian menyebutkan bahwa Budaya Kerja 5S yang meliputi Seiri (Pemilahan), Seiton (Penataan), Seiso (Pembersihan), Seiketsu (Pemantapan) dan Shitsuke (Pembiasaan) yang diterapkan diperusahaan secara bersama-sama bisa mempengaruhi kinerja karyawan (Wahyudi, 2017); (2) Pengaruh Budaya Kerja 5R dan Komunikasi Internal terhadap Semangat Kerja dan Kinerja Karyawan dengan metode penelitian Structural Equation modeling (SEM) menggunakan bantuan Software AMOS. Hasil penelitian menyebutkan bahwa Penerapan budaya kerja 5R berpengaruh signifikan dan positif terhadap semangat kerja karyawan. Terciptanya semangat kerja ternyata berpengaruh signifikan dan positif terhadap kinerja karyawan. Ini berarti semakin tinggi semangat kerja karyawan, maka akan semakin tinggi pula kinerja karyawan (Sari, 2015).

Penerapan Program Good Manufacturing Practices (GMP) dan Program 5P terhadap kinerja karyawan di PT. Kalbe Morinaga Indonesia dirumuskan dalam rerangka pemikiran berikut ini:

Gambar 1. Rerangka Pemikiran 


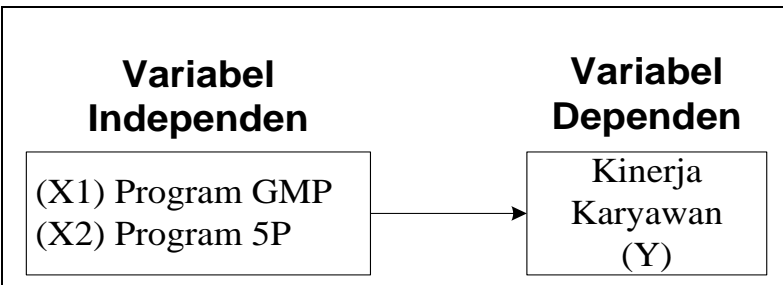

Berdasarkan rerangka pemikiran di atas, hipotesis penelitian ini dirumuskan sebagai berikut:

$\mathrm{Ha}_{1}$ : Program Good Manufacturing Practices (GMP) berpengaruh signifikan terhadap Kinerja Karyawan

$\mathrm{Ha}_{2}$ : Program 5P berpengaruh signifikan terhadap Kinerja Karyawan

\section{Metodologi Penelitian}

Penelitian ini dilakukan di PT.Kalbe Morinaga Indonesia alamat kawasan Industri Indotaisei Sektor 1A Blok Q. Adapun pelaksanaan penelitian ini dilakukan selama dua bulan yaitu bulan Mei 2018 sampai dengan Juni 2018.

Populasi penelitian ini adalah karyawan PT. Kalbe Morinaga Indonesia sebanyak 390 orang. Jumlah sample penelitian ini menggunakan metode rumus perhitungan slovin' (Sugiyono, 2015). Dengan memperhatikan data jumlah mahasiswa sebanyak 390 orang dan tingkat error $(e)$ dalam penetapan responden $=10 \%$, maka akan nampak perhitungan sebagai berikut:

$$
\mathrm{n}=\frac{390}{1+390.0,1^{2}}
$$

jadi n: 80 orang (dibulatkan)

Berdasarkan perhitungan di atas, jumlah responden yang dibutuhkan untuk kemudian diminta mengisi kuesioner dan dipergunakan jawabannya untuk penelitian ini adalah sebanyak 80 orang responden. Dan setelah dibagi secara proporsional ke setiap departemen menjadi total 84 orang dengan perincian: (a) Departemen HR \& GA $=12$ orang; (b) QA $=7$ orang; (b) Produksi $=38$ orang; (d) Engineering $=9$ orang; (e) Warehouse $=11$ orang; (f) FA \& IT $=3$ orang; dan (g) IOS \& MNF $=4$ orang.

Pengambilan sampel dilakukan dengan menggunakan teknik accidental sampling. Sampel penelitian ini adalah karyawan PT. Kalbe Morinaga Indonesia pada saat peneliti melakukan penelitian dan sampel dipilih secara acak.

Penelitian ini menggunakan metode SEM berbasis komponen atau varians regresi dengan pendekatan Partial Least Square (PLS). Pengujian ini dilakukan melalui uji validitas butir dan reliabilitas instrumen yang diawali melalui merancang inner model (inner relation, structural model dan substantive theory). Inner model menggambarkan hubungan antar variabel laten berdasarkan pada teori substantif. Structural Model dapat dievaluasi dengan menggunakan pendekatan $R$-square atas konstruk dependen, Stone-Geisser 
Qsquare test untuk predictive relevance dan uji t serta signifikansi dari koefisien parameter jalur struktural (Ghozali, 2006).

Model PLS ini dapat dinilai dengan melihat $R$-square untuk setiap variabel laten dependen. Interpretasinya sama dengan interpretasi pada regresi.Perubahan nilai $R$ square dapat digunakan untuk menilai pengaruh variabel laten independen tertentu terhadap variabel laten dependen apakah mempunyai pengaruh yang substantif (Ghozali $\&$ Latan, 2015).Disamping itu, melihat nilai $R$-Square, model PLS juga dievaluasi dengan melihat $Q$-square prediktif relevansi untuk model konstruktif. $Q$-square mengukur seberapa baik nilai observasi dihasilkan oleh model dan juga estimasi parameternya.

Convergent validity dari model pengukuran dengan model reflektif indikator dinilai berdasarkan korelasi antara item skor atau komponen skor dengan konstruk skor yang dihitung dengan PLS. Variabel independen X1 yaitu Penerapan Program Good Manufacturing Practices (GMP) direfleksikan melalui 16 (enam belas) indikator dari X1 - X16. Selanjutnya variabel X2 yaitu Penerapan Program 5P direfleksikan melalui 9 (sembilan) indikator dari X17 - X25 serta variabel dependen Y yaitu Kinerja Karyawan direfleksikan melalui 9 (sembilan) indikator dari Y1 - Y9. Ukuran reflektif dikatakan tinggi jika berkorelasi lebih dari 0,70 dengan konstruk yang ingin diukur. Namun demikian, pada penelitian tahap awal dari pengembangan skala pengukuran nilai loading 0,5 sampai 0,60 dianggap cukup (Ghozali \& Latan, 2015).

Discriminant validity dari model atas pengukuran dengan reflektif indikator dinilai berdasarkan cross loading pengukuran dengan konstruk. Jika korelasi konstruk dengan item pengukuran lebih besar daripada ukuran konstruk lainnya, maka akan menunjukkan bahwa konstruk laten memprediksi ukuran pada blok yang lebih baik daripada ukuran blok lainnya.

Metode lain untuk menilai discriminant validity adalah membandingkan nilai square root of Average Variance Extracted (AVE) setiap konstruk dengan korelasi antara konstruk lainnya dalam model. Jika nilai akar AVE pada setiap konstruk lebih besar daripada nilai korelasi antar konstruk dengan konstruk lainnya dalam model, maka dikatakan memiliki nilai discriminant validity yang baik. Pengukuran ini dapat digunakan untuk mengukur reabilitas component score variable laten dan hasilnya lebih konservatif dibandingkan dengan composite reability. Direkomendasikan nilai AVE harus lebih besar 0,50 Composite reability yang mengukur suatu konstruk dapat dievaluasi dengan dua macam ukuran yaitu internal consistency dan Cronbach's Alpha (Ghozali \& Latan, 2015).

Diagram jalur selanjutnya dikonstruksikan dengan tujuan untuk memvisualisasi hipotesis yang telah diajukan dalam konseptualisasi model teoritis ke dalam sistem persamaan berikut ini:

$\eta=\alpha+\gamma_{1} \xi_{1}+\gamma_{2} \xi_{2}+\zeta \ldots . .(1)$

Keterangan :

$\eta($ Eta) $\quad$ : Variabel endogen Kinerja Karyawan 
$\xi_{1-2}($ Ksi 1-2) : Variabel eksogen masing-masing variabel Good Manufacturing Practices (GMP) dan 5P.

$\gamma_{1-2}$ (Gamma 1-2) : Koefisien pengaruh masing-masing variabel laten yaitu Good Manufacturing Practices (GMP) dan 5P terhadap variabel endogen Kinerja Karyawan.

$\zeta$ (Zeta) : Kesalahan dalam persamaan yaitu antara variabel eksogen dan/atau variabel endogen terhadap variabel endogen.

Pengujian hipotesis menggunakan metode resampling bootstrap dengan melihat tstatistik dan nilai path-coefficient-nya. Nilai t-statistik menunjukkan signifikansi konstruk sedangkan path-coefficient merujuk pada sifat hubungan antar konstruk (positif atau negatif). Jika nilai $\mathrm{t}_{\text {value }} \geq \mathrm{t}_{\text {critical }}$ atau probabilitas signifikansi $<0,05 \mathrm{maka}_{\mathrm{a}}$ diterima atau sebaliknya. Hasil dari pembuktian hipotesis digunakan sebagai dasar untuk menganalisis pengaruh penerapan program Good Manufacturing Practices dan program 5P terhadap kinerja karyawan di PT. Kalbe Morinaga Indonesia.

\section{Hasil dan Pembahasan}

Survei penelitian ini dilakukan secara langsung dengan mendistribusikan kuesioner pada bulan Mei - Juni 2018 bulan kepada 84 (delapan puluh empat) responden yaitu karyawan PT. Kalbe Morinaga Indonesia dengan menggunakan perhitungan slovin pada presisi $10 \%$.

Tabel 1. Demografi Umum Responden

\begin{tabular}{cccc}
\hline \multicolumn{2}{c}{ Kategori Responden } & Jumlah & $(\%)$ \\
\hline \multirow{2}{*}{ Jenis Kelamin } & Pria & 64 & 76 \\
\cline { 2 - 4 } & Wanita & 20 & 24 \\
\hline \multirow{3}{*}{ Usia } & $19-25$ tahun & 19 & 23 \\
\cline { 2 - 4 } & $26-35$ tahun & 44 & 52 \\
\cline { 2 - 4 } & $>35$ tahun & 21 & 25 \\
\hline \multicolumn{3}{c}{ Sumber: Data Diolah (2018) }
\end{tabular}

Jumlah responden wanita sebanyak 20 orang memiliki persentase $24 \%$ dan pria sebanyak 64 orang memiliki persentase $76 \%$. Sebagian besar responden berada direntang usia 19 25 tahun yaitu sebanyak 19 orang $(23 \%)$ dan responden yang berada direntang 26 - 35 tahun sebanyak 44 orang (52\%) dan 21 orang responden memiliki usia direntang 35 tahun keatas dengan persentase $(25 \%)$.

Convergent validity dari measurement model dengan indikator refleksif dapat dilihat dari korelasi antara score item/indikator dengan score konstruknya. Indikator individu dianggap reliabel jika memiliki nilai korelasi di atas 0,70. Namun demikian, pada riset dalam tahap pengembangan skala, loading 0,50 sampai 0,60 masih dapat diterima (Ghozali \& Latan, 2015). Hasil pengolahan dengan menggunakan SmartPLS 3.0 dapat dilihat pada Gambar 2, nilai outer model atau korelasi antara indikator dengan variabel laten terdapat kurang dari 0,5 sehingga ada beberapa indikator yang harus dihilangkan yaitu indikator X8, X17, X19, X22, Y5 \& Y8.

Gambar 2. Model Struktural Awal 


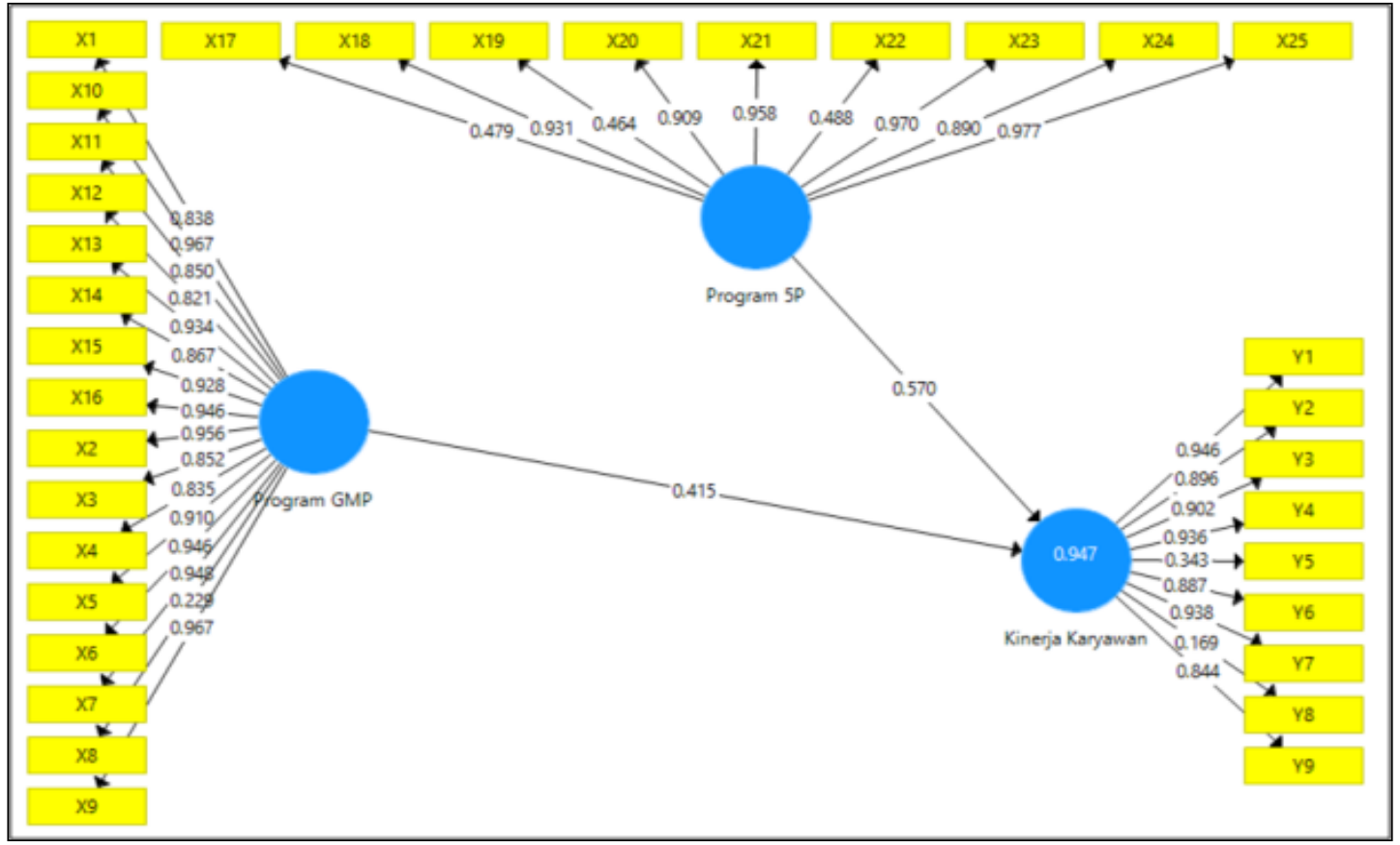

Hasil pengolahan dengan menggunakan SmartPLS 3.0 dapat dilihat pada Gambar 3, nilai outer model atau korelasi antara indikator dengan variabel laten hasilnya lebih besar dari 0,5 sehingga semua indikator pada konstruk dianggap reliable karena telah memenuhi convergent validity.

Gambar 3. Model Struktural Modifikasi

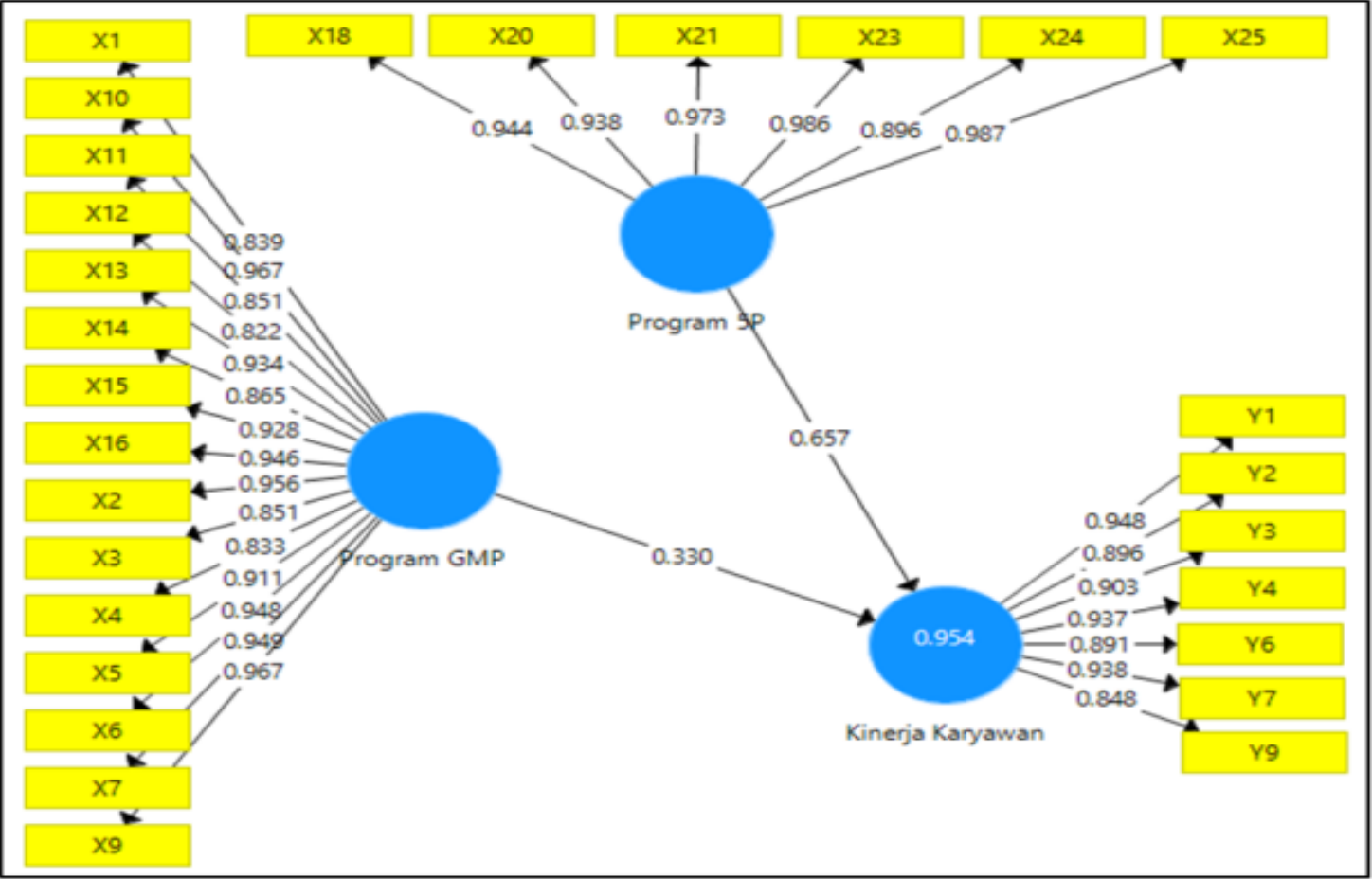

Discriminat validity dari model pengukuran dengan indikator refleksif dinilai berdasarkan cross loading pengukuran dengan konstruk. Jika korelasi konstruk dengan 
item pengukuran lebih besar daripada ukuran konstruk lainnya, maka hal itu menunjukkan bahwa konstruk laten memprediksi ukuran pada blok mereka lebih baik daripada ukuran pada blok lainnya. Cara lain mengukur discriminat validity adalah melihat nilai square root of average variance extracted (AVE). Nilai yang disarankan adalah di atas 0,5. Berikut adalah nilai AVE dalam penelitian yang dihasilkan pada Tabel 2 .

Tabel 2. Hasil Uji Discriminant Validity

\begin{tabular}{cc}
\hline Konstruk & $\begin{array}{c}\text { Nilai } \\
\text { Average Variance } \\
\text { Extracted }\end{array}$ \\
\hline Kinerja Karyawan & 0,827 \\
Program GMP & 0,821 \\
Program 5P & 0,911 \\
\hline \multicolumn{2}{c}{ Sumber: Output Smart PLS 3.0 (2018) }
\end{tabular}

Hasil pengolahan dengan menggunakan SmartPLS 3.0 dapat dilihat pada Tabel2, keseluruhan variabel konstruk memiliki nilai AVE di atas 0,5, hal ini berarti semua konstruk memiliki discriminat validity yang tinggi.

Tabel 3. Hasil Uji Composite Reliability

\begin{tabular}{lc}
\hline \multicolumn{1}{c}{ Konstruk } & $\begin{array}{c}\text { Nilai } \\
\text { Composite Reliability }\end{array}$ \\
\hline Kinerja Karyawan & 0,971 \\
Program GMP & 0,986 \\
Program 5P & 0,984 \\
\hline \multicolumn{2}{c}{ Sumber: Output Smart PLS 3.0 (2018) }
\end{tabular}

Hasil pengolahan dengan menggunakan SmartPLS 3.0 dapat dilihat pada Tabel 3, nilai composite reliability dari blok indikator yang mengukur konstruk. Suatu konstruk dikatakan reliable jika nilai composite reliability di atas 0,60 (Ghozali \& Latan, 2015). Hasil ini menunjukkan bahwa masing-masing konstruk memiliki reliability yang tinggi, hal ini dapat dilihat dari nilai composite reliability seluruh konstruk lebih besar dari 0,60.

Menilai inner model adalah mengevaluasi hubungan antar konstruk laten seperti yang telah dihipotesiskan dalam penelitian ini, yaitu bagaimana hubungan antar konstruk yang diukur dengan 45 indikator.

Tabel 4. Hasil Uji R-Square

\begin{tabular}{cc}
\hline Konstruk & $\begin{array}{c}\text { Nilai } \\
\text { R-Square }\end{array}$ \\
\hline Kinerja Karyawan & 0,954 \\
\hline \multicolumn{2}{c}{ Sumber: Output Smart PLS 3.0 (2018) }
\end{tabular}

Hasil pengolahan dengan menggunakan SmartPLS 3.0 dapat dilihat pada Tabel 4, nilai R-Square sebesar 0,954 untuk konstruk Kinerja Karyawan yang berarti bahwa Kinerja 
Karyawan yang dapat dijelaskan oleh variabilitas konstruk Program GMP dan Program 5P adalah sebesar 95,4\% sedangkan sisanya 4,6\% dipengaruhi oleh faktor-faktor lain.

Pengujian hipotesis dilakukan dengan metode bootstrapping dengan menggunakan uji two-tailed pada tingkat signifikansi 5\%. Hipotesis tersebut akan diterima jika memiliki tvalue lebih besar dari 1,96 (Hair, Black, Babin, \& Anderson, 2010). Dalam penelitian ini, hipotesis akan diterima jika nilai t-value di atas 1,96 (t-table) untuk p-value kurang dari (<) 0.05 .

Tabel 5. Hasil Uji Hipotesis

\begin{tabular}{ccccc}
\hline Hipotesis & $\begin{array}{c}\text { Original Sampel } \\
(\mathbf{O})\end{array}$ & t-stat & Sig. & Kesimpulan \\
\hline $\begin{array}{c}\text { Ha1. Program GMP } \rightarrow \\
\text { Kinerja Karyawan }\end{array}$ & 0,330 & 2,534 & 0,012 & Signifikan \\
\hline $\begin{array}{c}\text { Ha2. Program 5P } \rightarrow \\
\text { Kinerja Karyawan }\end{array}$ & 0,657 & 4,893 & 0,000 & Signifikan \\
\hline \multicolumn{4}{c}{ Sumber: Output Smart PLS 3.0 (2018) } \\
\end{tabular}

Berdasarkan hasil pengujian hipotesis pada Tabel 5, maka dijelaskan interpretasi penelitian sebagai berikut:

$\mathrm{Ha}_{1}$. Program GMP terhadap Kinerja Karyawan

Konstruk Program Good Manufacturing Practices berpengaruh positif mempengaruhi Kinerja Karyawan dimana t-value $(2,534)>\mathrm{t}$-table $(1,96)$ dan $\mathrm{p}$ values $(0,012)<0.05$. Hal ini berarti bahwa variabel Program Good Manufacturing Practices berpengaruh secara positif terhadap Kinerja Karyawan PT. Kalbe Morinaga Indonesia "Diterima". Dari hasil pengujian konstruk Program Good Manufacturing Practices dan melihat indikator yang paling berpengaruh hendaknya perusahaan dapat terus menjaga kualitas kemasan produk yang digunakan sehingga bisa melindungi produk dan sesuai dengan persyaratan mutu, mempertahankan karyawan perusahaan yang dianggap sudah mempunyai kompetensi dan memiliki tugas secara jelas dalam melaksanakan program keamanan produk dan terus melakukan monitoring dan perawatan bangunan area produksi yang sudah dirancang sedemikian rupa sehingga memenuhi hygiene pangan serta melindungi produk dari kontaminasi silang.

Ha2. Program 5P terhadap Kinerja Karyawan

Konstruk Program Good Manufacturing Practices berpengaruh positif mempengaruhi Kinerja Karyawan dimana t-value $(4,893)>\mathrm{t}$-table $(1,96)$ dan pvalues $(0,000)<0.05$. Hal ini berarti bahwa variabel Program $5 \mathrm{P}$ berpengaruh secara positif terhadap Kinerja Karyawan PT. Kalbe Morinaga Indonesia "Diterima". Dari hasil pengujian konstruk Program 5P dan melihat indikator yang paling berpengaruh hendaknya dapat terus memelihara kedisiplinan pribadi dan kelompok terkait pelaksanaan Program 5P, menjaga kebiasaan membuang sampah pada tempatnya dan juga kebiasaan karyawan membersihkan semua barang, fasilitas, dan lingkungan kerja.

Hasil diatas sesuai dengan penelitian terdahulu Wahyudi (2017) yang melakukan penelitian tentang Penerapan Budaya Kerja 5S dan pengaruhnya terhadap Kinerja 
Karyawan dimana hasilnya menyebutkan bahwa Budaya Kerja 5S yang meliputi Seiri (Pemilahan), Seiton (Penataan), Seiso (Pembersihan), Seiketsu (Pemantapan) dan Shitsuke (Pembiasaan) yang diterapkan diperusahaan secara bersama-sama dapat mempengaruhi kinerja karyawan.

\section{Simpulan}

Berdasarkan hasil penelitian maka dapat ditarik kesimpulan sebagai berikut (1) Program Good Manufacturing Practices (GMP) berpengaruh secara positif terhadap Kinerja Karyawan di PT. Kalbe Morinaga Indonesia dan (2) Program 5P berpengaruh secara positif terhadap Kinerja Karyawan di PT. Kalbe Morinaga Indonesia.

\section{Daftar Pustaka}

Ghozali, I. (2006). Structural Equation Modeling - Metode Alternatif dengan Partial Least Square (Edisi 3). Semarang: Universitas Diponegoro.

Ghozali, I., \& Latan, H. (2015). PLS Konsep, Teknik dan Aplikasi Menggunakan Program Smartpls 3.0. (Edisi Kedua). Semarang: Universitas Diponegoro.

Hair, J.F. et al. (2010). Multivariate Data Analysis (7th ed.). New Jersey: Prentice Hall.

Hirano, H. (1996). 5S For Operators: 5 Pillars. Portland: [PPDT] Productivity Press Development Team.

Mangkunegara, A.A. (2013). Manajemen Sumber Daya Manusia Perusahaan. Cetakan ke-11. Bandung: PT. Remaja Rosdakarya.

Osada, T. (2011). Sikap Kerja 5S. Jakarta: PPM Bisnis 2030.

Sari, R.K. (2015). Pengaruh Budaya Kerja 5R dan Komunikasi Internal terhadap Semangat Kerja dan Kinerja Karyawan. Widya Cipta, VII(2), 141-154.

Sedarmayanti. (2014). Manajemen Sumber Daya Manusia, Reformasi Birokrasi, dan Manajemen Pegawai Negeri Sipil. Cetakan ke-7. Bandung: Refika Aditama.

Sugiyono. (2015). Metode Penelitian Kombinasi (Mixed Methods). (M. Sutopo, Penyunt.). Cetakan ke-5. Bandung: CV. Alfabeta.

Sutikno, N. (2017). Penerapan Good Manufacturing Practices (GMP) Dalam Produksi Ikan Kaleng Di PT. Maya Food Indutries Pekalongan, 1-67. Laporan Kerja Praktek. Universitas Soegijapranata. http://repository.unika.ac.id/15575/ 1/15.I1.0106\%20Novani\%20Sutikno.pdf

Thaheer, H. (2008). Sistem Manajemen HACCP. Jakarta: PT Bumi Aksara.

Tonic, N. et al. (2014). Manufacury Effectiveness Improving Using Lean and 5S,8th International Quality Conference. 417-425. http://www.cqm.rs/2014/cd1/ pdf/papers/focus_2/044.pdf

Wahyudi. (2017). Penerapan Budaya Kerja 5S dan Pengaruhnya Terhadap Kinerja Karyawan. Jurnal Teknoterap, 1(1), 49-80.

Winarno, F. G. (2008). Kimia Pangan dan Gizi (Edisi Terbaru). Jakarta: Gramedia Pustaka Utama.

\section{Copyright Disclaimer}

Copyright for this article is retained by the author(s), with first publication rights granted to the journal. 